\title{
Is Hyper-textual Learning a Challenge for Traditional Religious Education?
}

\author{
Seyed Mahdi Sajjadi \\ Tarbiat Modares University \\ Iransajadism@modares.ac.ir
}

\begin{abstract}
One of the outcomes of the expansion and growth of information technology is the predominance of hyper-textual learning space and consequently the weakening of the role and place of texts in learning and education processes, especially in traditional religious education. Substituting hyper-textual learning space to texts-based learning can bring about some outcomes for the text-based religious education process. The present paper aims to study challenges and problems created by hyper-textual learning space for the traditional religious education process.
\end{abstract}

\section{Introduction}

Today, educational systems are influenced by technological innovations. Technological changes welcomed as a means to enhance the functional and communicative contexts into which it is placed yield such strategic outcomes as increased accessibility, acceleration and flexibility, as well as maximized productivity. These technological changes and developments, in creating and propagating special spaces and facilities, could alter forms of social, cultural, political and, particularly, educational practices. What is at stake in technical innovation is not merely an increased efficiency of interchange, enabling new ways of investment and increased productivity at work, but rather an extensive change and development in culture and in the way identities are structured. Amongst these technological changes, information technologies intrinsically invoke modes of communication, understanding and practice that disorient accepted, modern categories/conceptions of identity, subjectivity, and knowledge, as well as various forms of cultural, textual, and pedagogical authority. One of the main consequences in the development of information technology is how information technology dominates the role and status of hypertext and, consequently, weakening the status of text in educational processes. In fact, information technology, with an appeal to hyper-textual spaces, alters educational programs and behaviors. This is because, in hyper-textual space, we are experiencing a qualitatively new form of knowledge and a qualitatively new way of constructing both knowledge and educational practices. In religious education, religious fixed texts have the most important status and role and teachers justify their religious views and instruction based on these fixed and predefined religious texts. As such, the main question of this paper is what are the consequences and challenges of appealing to the hyper-textual spaces in the text-based religious education process. To begin, I will discuss the concept of text and hypertext as outlined below.

Journal of Contemporary Issues in Education, 2009, 4(1), pp. 57-70.

ISSN 1718-4770 @ 2009 University of Alberta

http://ejournals.library.ualberta.ca/index.php/JCIE 


\section{Text and Hypertext}

Text (according to the Oxford English Dictionary) is the "wording of anything written or printed; the structure formed by the words in their order; the very words, phrases, and sentences as written." Such a definition allows for text to be considered as both written words in general and, more holistically, as the combination of such written words to form a structure that produces meaning. Thus, the definition of text moves between text and textuality, moving from a singular word or symbol to a symbolic structure woven by the threads of language. Here, the history of the word text itself becomes crucial; text, stemming from text-ere (to weave), is the "tissue of a literary work... Literally that which is woven, web, texture." As a texture, text is the weaving of words, ideas, and meaning and it is also, most importantly, a texture spun by language, which in theory, has become destabilized, a tangle of meaning and symbol. Therefore, text, as textuality, has become a site of theoretical criticism and argument as the identity of the true spinners of text is called into question. That is to say, theoretical movements have begun to examine where meaning lies within text and asking the question, who contributes to the final pattern? Does meaning emerge from authorial intention, from the structure of the text itself, or from the reader's own contributions (Goldman, 1998)? The pattern and threads of text have unraveled, leaving literary and linguistic theorists to weave together the structures of language and meaning to determine the limits and pathways created by text.

Text, defined by the Oxford English Dictionary, is also "the body of any treatise, the authoritative or formal part as distinguished from notes, appendices, introduction, and other explanatory or supplementary matter." Within its own definition, text implies authority: the final word. Thus, we find ourselves quoting "the text" to prove a point, using "textbooks" to locate fact and truth. This notion of text, as authoritative, reaches back to the Old Testament and the biblical tale of the Ten Commandments. When Moses revealed the inscribed tablets, he reveals the word of God; thereby, the written language has, from its mythical origins, been associated with the divine. The phonetic alphabet, according to the Old Testament, replaces the making of images and the written language thus becomes a paradigm for media, replacing images, and laying claim to spiritual authority.

The traditional understanding that accompanies the idea of the text as authority is that of the work as closed, finished, a final product to be deciphered. Such a notion relies on structuralist thought, which posits language as a structure in which the relationship of words with one another produces a stable, unified meaning. This picture of language as a complex and solid structure grows out of the work of Ferdinand de Saussure (1996) in Course in General Linguistics. For Saussure, language is not merely "a list of words, each corresponding to the thing that it names," but a system of arbitrary linguistic signs that, when viewed in relationship to one another, create a universal, fixed system of meaning (Saussure, 1996). As the relations between words, rather than the words themselves, are determiners of meaning, binary opposition is a fundamental to structuralist thought (Edgar \& Sedgwick, 1999). Thus, meaning emerges from opposition, (i.e. we know light from dark and dark from light) and oppositional relationships function as stable pillars that support language structure. 
This structuralist understanding of language posits the text as fixed, a work which displays a stable structure of meaning. In this way, as Alan Goldman writes, "We do not perceive ink marks and infer that they are there to represent meaningful words. Instead, we directly perceive words and sentences, and, if we understand the language being used, agree on their standard meanings" (Goldman, 1998, p. 502). Structuralism recognizes meaning as stable and, therefore, authorial intention may be successfully realized through the production of the text, a work created by a fixed system of language and meaning. That is, we may search for a unified, universal meaning within the text, and we may attribute that meaning to the author, who we assume has successfully used a stable system of language. However, even if the author has failed and his or her intention does not match with the text, that is the fault of the author and not of language; the text retains a stable meaning. Within such thought, the texture of text remains a tightly-woven system of signifiers and signified.

Jacques Lacan (1968), in The Function of Language in Psychoanalysis, disrupts the structuralist production of meaning by revealing fractures in the signifying system. For Lacan, signifiers float above the signified, creating a structure under which the signified may shift and slide. The link connecting signified to signifier is dissolved and entrance into language becomes the advent of desire. As Lacan (1968) writes: "Man speaks therefore, but it is because the symbol has made him man". Thus, rather than controlling a stable system of language, language controls us, and we encounter a symbolic that forms our subjectivity. Lacan, in revealing these rips between signs and meaning, destabilizes the system of language. Moreover, he reveals that language controls the author, who himself is created by that language. Searching for the authorial intention behind text thus seems inapplicable, for the structure of language slides out of the hands of the author, as well as our own.

Though Lacan reveals a split between the structure of language and that which it signifies, Roland Barthes attacks structuralism on a different level and dismantles the fixed structure of meaning within text, allowing the text to be a texture whose meaning is woven by the work of the reader. That is to say, rather than viewing the text as a fixed system of meaning, Barthes understands the text as open and incomplete, as one awaiting the input of an engaged reader. Barthes is central among a group of post-structuralist theorists who elaborated on the productivity of text in the French journal, Tel (Ducrot \& Todorov, 1972). These theorists, including Barthes, Jacques Derrida, and Julia Kristeva, contributed to the discussions of text as a textuality, an unfinished work, able to produce a plurality of meaning (Todorov, 1972). Though Barthes began his career adhering to the principles of structuralism, in his later works such as $S / Z$, Barthes moved into a poststructuralist position, accepting the view that text moves beyond the limits of structuralism to a plurality of meaning that lies in the hands of the reader (Edgar \& Sedgwick, 1999). Like Lacan (1968), Barthes believed that language, and not the author, has control. In his essay, "The Death of the Author," Barthes explains that the author, heretofore seen as "the final signified," and the creator of textual unity, is not the final authority on a text (Seban, 1998). Instead, Barthes declares that the author is, in actuality, a mere scriptor who produces a text that speaks for itself, and whose speech is then interpreted, on various levels by the reader (Seban, 1998).

In understanding the text as speech, Barthes escapes the notion of the text as final and closed, and he inverts one of the ancient arguments against the written language in 
order to proclaim the openness and life of text. Plato claims that "once written down," speeches "are tumbled about anywhere among those who may or may not understand them, and know not to whom they should reply, to whom not: and, if they are maltreated or abused, they have no parent to protect them; and they cannot protect or defend themselves" (Jowett, 1937). For Plato, the author is absent in the written word, and the author's absence ensures the absence of any kind of proactive and engaged reading; spoken discourse is the true medium. However, Plato ironically posits his ideas in the written language. He writes in dialogue, perhaps in order to grant primacy to speech even within his writing.

However, Plato's written dialogue, though a critique of written text simultaneously embodies the value of text by bringing speech to the page and, more importantly, by inviting the reader into the discussion; Plato himself creates a textuality that weaves an active reader into the work. It is this textuality to which Barthes refers in calling the text a speech. For Barthes, the text does not coldly present meaning to the reader, as Plato would have it, but, rather, engages the reader who then creates meaning from the text. Text offers pathways rather than limits, and blank margins serve as the reader's space in which to expand upon and grow from the printed words. As Barthes claims: "The text you write must prove to me that it desires me" (Barthes, 1982). Thus, reading becomes active and productive, what Wolfgang Iser refers to as "something like an arena in which reader and author participate in a game of the imagination" (Iser, 1974).

Though, like Lacan, Barthes (1977) recognizes language as, in a sense, acting on its own. Unlike Lacan, Barthes' reader does not become what language creates but uses the displacement of the signified to create a plurality of meaning; we are not controlled by language but rather use the fractures in the system to create new meanings, new pathways for language. In this sense, post-structuralism, as developed by Barthes, denies the idea that interpretation consists in determining the meaning of a text. It moves away from the text as a completed whole and opens the text up to reader contribution, thereby reuniting the notion of text with its original connotations of textuality: a weaving of meaning and ideas. Thus, text moves beyond the limits of structuralism and meaning reaches beyond any stable structure supposedly offered by the relationships of the printed words.

The progression from the idea of the text, a completed work with a unified meaning, to text, a textuality weaving author, language, and reader to form limitless readings and a plurality of meaning, reveals the continual progress of critical discourse in examining the systems of language and the possibilities of text to provide structure as well as freedom to the active reader. This renewed sense of text as textuality renders the function of text as vital to systems of media in which ideas and meanings are submitted to systems of signs and gestures, which, in turn, communicate meaning, thwart meaning, and create new meaning, often through the textuality of text.

Due to technological changes and developments, the concept, nature and function of text is altered. Today, the reader is not limited by written, hard and fixed (book) texts due to the fact that the reader relates to other spaces such as hypertexts. Of course, there are many more differences between text and hypertext. Text is based on a sequential method of reading. Landow and Delany (1991) refer to the printed text as linear, bounded, structured in certain logic and fixed. According to Wills (1999): 
Text has a particular focus, a clearly-defined audience and a single voice. Another tenet of the print medium has been the creation of the canon: the chosen texts are assumed to contain the central authoritative 'truth' of a discipline. By staying available in print, these retain their central role (Wills, 1999, p.102).

Based on distinctions outlined by Barthes (1977) between "work and text," text is as a methodological field, a social space that decants the work from its consumption and gathers it up as play, activity, production and practice. Text is usually organized into chunks, units, or nodes, as they have come to be known, and the links form connections between certain nodes (McKnight, Dillion \& Richardson, 1996). In Berg and Watt's view, the most standard text documents are constructed to be read, linearly, from the beginning, page to the ending page (Berg \& Watt, 1991).

Today, hypertext also is an undeniable part of learning and teaching processes. Hypertext refers to a wide variety of reading/writing and discursive activities that are activated vis-à-vis the World Wide Web through HTML. It will increasingly become the method of future classroom research, reading and writing practices. In Renear's view, texts are:

- Real: They have properties independent of our interests in them and our theories about them.

- Abstract: The objects which constitute texts are abstract, not material, objects.

- Intentional: Texts are, necessarily, the product of mental acts

- Hierarchical: The structure of texts is fundamentally hierarchical

- Linguistic: Texts are linguistic objects; rendition features are not parts of texts, and therefore not proper locations for textual meaning (Renear, 1997).

The term, hypertext, was first advanced by Ted Nelson in 1960. According to his vision: "hypertext would be a dynamic and interactive environment that allowed the user to customize the process of retrieving and organizing information, facilitating instantaneous traversals of divergent textual materials across and through disciplinary boundaries" (Nielsen, 1990, p. 121). It is based on a non-sequential method of reading, an active and generative mode of interpretative production, and, at the same time, would provide a reversible media in which reading and writing would be integrated into a single, mutually-constitutive digital format (Landow, 1997). The prefix "hyper" usually means "more than," so we may begin by asking what is it that hypertext has that makes it more than text (McKnight, Dillion \& Richardson, 1996)? Also, the prefix hyper- comes

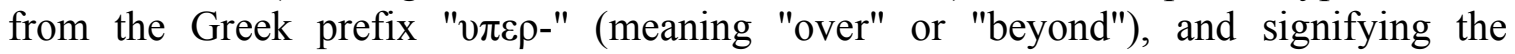
overcoming of the old linear constraints of written text. The term "hypertext" is often used where the term hypermedia might seem appropriate. In 1992, Ted Nelson-who coined both terms - wrote:

By now the word "hypertext" has become generally accepted for branching and responding text, but the corresponding word "hypermedia," meaning complexes of branching and responding graphics, movies and sound-as well as text-is much less used. Instead they use the strange term "interactive multimedia"-four 
syllables longer, and not expressing the idea that it extends hypertext (Nelson, 1992, p. 82).

Hypertext most often refers to text on a computer that will lead the user to other related information on demand. Hypertext represents a relatively recent innovation to user interfaces which overcome some of the limitations of written text. Rather than remaining static like traditional text, hypertext makes possible a dynamic organization of information through links and connections (called hyperlinks). Hypertext can be designed to perform various tasks; for instance when a user "clicks" on it or "hovers" over it, a bubble with a word definition may appear, a web page on a related subject may load, a video clip may run, or an application may open.

The term hypertext has been used, over the last 30 years, to describe an extension to the traditional form of "flat," or linear, text. For example, a book can be described as being linear because it is usually read from the beginning to the end. Recent developments in computer systems, however, have allowed programmers to develop new ways in which traditional text can be viewed. Conklin (1987) describes how these systems allow references to be created between different chunks of text, which can be in the same or another document. This type of text is called nonlinear text, or hypertext, because the pathway through the document branches off to other documents via these references (Conklin, 1987).

Three of the main contributors to the area of hypertext were Vannevar Bush, Douglas Engelbart and Theodore Nelson. In 1945, Vannevar Bush predicted a rapid growth in scientific literature and the need to create a way in which this large body of information should be browsed. In his article, Bush (1945) describes how the human mind works by associating related pieces of information. He applied this concept to a machine, called the "Memex" which allowed the user to tie two relevant pieces of information, from two separate documents, together. This idea of association is credited as being the first attempt to describe hypertext (Bush, 1945).

In 1963, Engelbart described a computer system that would augment man's intellect by allowing the user to interact with the system using special cooperative devices. As a result, the amount of information that a user could manipulate and understand would steadily increase, effectively "amplifying" the native intelligence of the user. The NLS system was implemented five years later at the Stanford Research Institute. It allowed users to create any number of links between elements within a document and between the documents themselves (Engelbart \& English, 1968).

During the development of the NLS, Ted Nelson was also developing his own ideas about augmentation. Nelson's system would only allow the storage of documents in their original format and any modifications made to these documents, e.g. a different paragraph, etc. By using links between these modifications and the original documents, previous versions could be easily reconstructed. New links could easily be created between different bodies of text and therefore new pathways could be formed through the material. It was from this system of linking large bodies of text together that Ted Nelson created the term hypertext (Nelson, 1992).

Contrary to printed text, hypertext is interactive, non-linear, associative, nonfixed, modular, and not necessarily owned by an identified single author (Wills, 1999). In Landow's view; 
Hypertext is composed of blocks of words (or images) linked electronically by multiple paths, chains or trails in an open-ended, perpetually unfinished textuality described by the terms link, node, network, web or path (Landow1997, p. 132).

Some thinkers tried to compare the hypertext to a constructivist learning environment which is predicated in "the ways... knowledge is mediated, interpreted, and created through individuals' interaction with their environment" (Popkewitz, 1991, p. 72). Hypertext is based on its relational matrices of connectivity and in the experimental, divergent, and contingent condition in which that connectivity is caught up. Some other thinkers such as Poster (1995) and Moulthrop (1994) also tried to compare hypertext to Deleuze and Guattari's advocation of a "rhizomatic" (anti)epistemology. According to Moulthrop (1994), hypertext seems to closely parallel Deleuze and Guattari's notion of the rhizome, in its decentralization of networks of information and knowledge, and its shift from textuality to an accelerated intertextuality and multi-textuality. The rhizome metaphor is used extensively when talking about hypertext theory and is very appropriate because rhizomes are non-hierarchical (Moulthrop, 1994).

Landow (1997) argues that hypertext enables a paradigm shift; a move toward a new epistemology and a move toward poststructuralism. Hypertext systems mimic Derrida's emphasis on discontinuity (Landow, 1997). Staninger (1994) believes that;

To understand the text of a book, the reader must try to comprehend the ego and intentions of the author. In hypertext, the roles are reversed, and this is the essential intellectual challenge for the authors. The logic and organization is created by the user, as he or she reads and interacts with the database (Staninger 1994, p. 63).

Hypertext gives permission to readers to insert themselves into the meaning construction process and write a text in a way that is often different from what the author foresaw. Birkerts (1994) believes that "electronic text and hypertext in particular, is killing the author." Hypertext readers, however, can challenge a text immediately or as immediately as the reader can write a response and link that response to the author's text. Foucault's (1977) emphasis on loosening of the "author's constraint over text" and hypertext seems to be one way in which this can happen. Following are the main characteristics of hypertext - especially when it is compared to text:

\section{Contrary to text, hypertext has no center, beginning or ending.}

In a hypertext network, there is no beginning or ending, no up or down, no in or out, no center or margin (Bolter, 1993). When one electronic text is linked to another text, or when one text is copied and pasted into another, the notion of a separation or a distinction between texts simply evaporates (Lanham, 1993).

\section{Hypertext blurs the distinction between author and reader.}

In "exploratory hypertext" (Joyce, 1988), the reader must pick and choose their way from node to node, thus determining the text to be read. The reader of a hypertext is always at least the co-author of the text that is read; sometimes the reader is the primary author. The reader can genuflect before the text or spit on its altar, add to a text or subtract from 
it, rearrange it, revise it, suffuse it with commentary. The boundary between creator and critic simply vanishes (Lanham, 1993).

3. Hypertext is changing, fluid. Not fixed or single.

Bolter says, "there is no single story of which each reading is a version, because each reading determines the story as it goes. We could say that there is no story at all; there are only readings" (Bolter, 1993, p. 14). Lanham also believes that the electronic text is "fundamentally unstable, restless, prone to change and likely to disappear" (Lanham, 1993). Contrary to hypertext, the linear language of the printed page encourages a single and clear point of view.

4. Hypertext is collaborative.

Hypertext can put the teacher and the student closer to the same level, promote interdisciplinary collaboration between scholars and encourage the integration of a scholar's teaching with her or his research. Within a hypertext environment, all writing becomes collaborative writing, doubly so.

The first element of collaboration appears when one compares the roles of writer and reader, since the active reader's necessary collaboration with the author produces a text via the choices he or she makes. The second aspect of collaboration appears when one compares the writer with other writers - that is the author who is writing now with the virtual presence of all writers "on the system" who wrote then but whose writings are still present (Landow, 1997).

\section{Hypertext is democratic and anti-hierarchical.}

The history of information technology from writing to hypertext reveals an increasing democratization or dissemination of power. Writing begins this process, for by exteriorizing memory it converts knowledge from the possession of one to the possession of more than one. Writing can belong to anyone; it puts an end to the ownership of selfidentical property that speech signaled. The democratic thrust of information technologies derives from their diffusing information and the power that such diffusion can produce (Landow, 1997, p. 143). The electronic media, by putting power into the hands of ordinary people, are proving to be a surprising force for democracy, rather than the ultimate nightmare of totalitarian control (Bolter, 1993). In Gerald's view, hypertext can provide the arena in which ethical and political arguments can take place. The wisest response to the canon wars raging in literary studies today is to "teach the conflicts" (Gerald, 1992). As a diverse multi-linear network, hypertext can readily incorporate conflicting arguments and interpretation; it can "encompass conflicting possibilities" (Bolter, 1993).

\section{Hyper-textual learning and Traditional Religious Education}

On the one hand, information technology creates opportunities for education and, on the other hand, it gives way to new problems that become challenges for religious education. One of the opportunities to attract the attention of educational philosophers recently is the rise and manifestation of electronic texts or hyper-textual learning space 
(Duncan, 1997). Hypertext has changed most aspects of our lives and work. This new style has manifested the presentation of changing information in reading, as well as research, and understanding methods. By this reason, hypertext has quickly attracted our attention. Of course, epistemological outcomes of this technology also attract the attention of thinkers. Landow (1997) believes that we must leave the systems, regimes of truth, or philosophies that put emphasis on ideas such as center, margin, hierarchy and linear communication, as well as those that stress systems that are based on multilinearity, links and networks (Landow, 1997). Peters (1996) has also pointed to the poststructural quality of hypertext in his discussions on "critical literacy." He says, that "ideas like virtual-text have come across new forms that have deadlocked traditional research methods" (Peters \& Lankshear, 1996, p. 48). Burbules and Callister (1996) believe that hypertext has a post-structural aspect and, exactly for this reason, hypertext is also a rhizomatic structure, a structure without centrality. "In hyper-textual space, form and content are separated from each other" (Burbules \& Callister, 1996).

Hypertext executes deep effects on moral, social, political and religious issues. As such, Winner (1986) stresses that technology helps not only human activities but also serves as a powerful force that transforms human activities and their meaning (Wills, 1999). With the increasing power and strength of information technology, new opportunities have been created in select educational process. Shifting in educational models from teacher-based to learner-based, and the substitution of text with the hypertextual space, are outcomes of the advancement in information technology.

Hyper-textual learning has challenged traditional assumptions about the role and place of teachers, authority and validity of texts, teaching methodologies, value of knowledge and conditions of educational practitioners. In the meantime, religious texts that were enjoying higher authority and validity by relying upon divine truths, metaphysics or meta-narrative, have been influenced by hypertext more than any other texts. In the process of transferring religious messages though, written, constant and printed texts have always possessed particular status. But hypertext, by crossing the traditional and fixed meaning that have dominated on behaviors, beliefs, socio-religious values and breaking the credibility of above texts, creates problem for the transitional process of these religious messages. As such, Wills (1999) believes that hypertext distributes information through horizontal communication and participation of people and, as a result, breaks the traditional hierarchical connection inside the texts and encounters the false and deceitful distance between texts or authors and reader to this fundamental criticism (Wills, 1999). According to Landow (1997), hierarchical and vertical methods of reading a text or book in a hyper-textual space lose their centrality and, consequently, weaken hierarchical, conservative and dualistic viewpoints about knowledge (a view prevalent to the religious education process). These are some of the important traces of the prevalence of hypertext spaces in learning and education process. From the point of view of Duncan (1997), hypertext minimizes distinction and detachment between authors and readers, providing ground for diverse interpretations other than those of author, and placing the values of all interpretations and ideas on an equal and symmetrical level. As such, instead of concentrating on forms of narrative text reading, the process moves towards strengthening different sounds that provide ground for the death of the author (Pagano, 1995). Hypertext puts emphasis on the role of reader and strengthens the relativistic epistemology; whereas, traditional religious education 
process focus attention on the viewpoints of author (speech of almighty, messengers, pious and religious elites) thus preventing the emergence of relativism-individualism in the interpretation of religious texts.

None of the texts can claim to have centrality and priority in hyper-textual space and all of them enjoy some relativity (Burbules \& Callister, 1996). This seems contrary to the manifestation of centrality and priority in religious texts that are considered basic in traditional religious education. The religious texts influence the addressee directly and strengthen the reader's commitments to the messages and hidden meaning of the texts. However, hypertext weakens the direct and face to face (in presence of teacher, text and student) learning processes that are usually suitable to control and influence students as well as the transfer and inducement of particular messages by religious elites or teachers. As such, the weakening role and place of teachers, as transferors of knowledge and information, is considered one of the new challenges posed by the hypertext-based learning. According to Duncan (1997), the elimination of clear and decisive distinction between authors and readers weakens the idea of "education as transfer of knowledge" which had enjoyed an eminent epistemological position for years, especially in traditional religious education. However, critics of hypertext emphasize the fact that hypertext hinders a reader from deep knowledge and understanding of texts, by keeping him or her at the surface of text, in encouraging him/her towards individualistic and relativistic interpretations of a text (Whalley, 1990). Reaching towards a deeper understanding of the text, as has been the actual view of the author, is considered as one of the aims of traditional religious education. However, this aim is also unascertained unless we give a principle role to the author and not to the reader. Similarly, critics of hypertext believe that movement in hyper-textual space means that students may have their own point of view once they encounter a text, and thus, might interpret same in any way they desire (Landow, 1997) with individual meaning making being perceived as meaningless in traditional religious text-based education.

In hyper-textual space, there does not exist any apriori and aposteriori, therefore meaning and purpose could lead to each making his or her own meaning in hypertext (Whalley, 1990). This in itself may lead to the conclusion that we encounter creative and relativistic interpretations in a way where it is impossible to avoid such interpretations and viewpoints in hypertext space. Here, knowledge would also essentially become an individual subject that comes into being through a person's interactions with his or her space (hyper-textual space). Individualistic knowledge and interpretations have little importance or place in textual-based religious education because in traditional religious education, knowledge is based on authority and centrality of religious texts (Barbules \& Callister, 1996), and readers (teachers or students) cannot escape from the power or intention and purpose of the author or take up meanings that they themselves have selected.

In religious education, the teacher tries to bring a close relationship between readers (students) and intention and purpose of the authors. Because, a religious text is based on a collection of recommendations, obligations and teachings that have roots in meta-narratives, these recommendations are not changeable and fluid (Roy, 2003). We have already pointed, contrary to what has been identified in hypertext as the "death of author" (Birkerts, 1994), or fading away of the distinction between author and reader, that the author possesses a real role in religious education processes and understandings, 
where the purpose of the author is considered as one of the main aims of the process and because religious text is neither participative nor liable to be interpreted and paraphrased in a deconstructive style, rather, it is a superior speech presented to the reader, beyond all participative process.

By weakening the idea of the teacher as a transferor of knowledge, and by emphasizing meaning making through the reader (student), as well as emphasizing the participative role of students in text or meaning production, hypertext tries to place students at par with teachers (Landow, 1997), hence, weakening the place of the teacher in education and the learning process; where the teacher is an interpreter of text, as well as transferor of meaning, in education. There exists an abundance of texts that must be interpreted or transferred mainly through teachers because it is not possible to interpret and define those texts through students, as all of the texts are not liable to be interpreted. Apart from imparting and transferring knowledge, teachers are also role models for students in religious education due to their already acquired higher information and knowledge platforms. However, this role and place become meaningless in hyper-textual spaces.

One other specialty of a hyper-textual space is to provide a possibility and opportunity for the manifestation of conflictive and distinctive ideas (Gerald, 1992). Resulting from such a possibility, is the strengthening of distinction, difference and oppositeness of people's viewpoints towards everything, including religion, and similarly strengthening heterogeneity, incompatibility and, in the process, strengthening divergence in the behavior of students in a manner that the possibility of the behavioral guidance of students toward similar and congenial aims may decrease. Strengthening equal and compatible aspects in the behavior of students or identifying some movement towards mental and behavioral convergence are considered one of the aims of the traditional religious education process. The convergent religious education process is also due to the presence of constant texts and predefined meaning on one side, and the lack of relativistic and individualistic, interpretative capability of most religious texts, on the other hand. Any disturbance in the above rule means creating challenges to text-based religious education because mental and behavioral convergence in religious and moral education is a main feature of a religious education process.

It is the case, therefore, that activities in hyper-textual learning spaces would be different from learning based on predefined, coded and limited texts, and different from movement in striated space. Striated space is a rational and pre-determined space, named by Parker Rees (2000), as a "ballistic approach." Religious education principles, like epistemic and behavioral disciplines, representation and hierarchy, largely manifest a ballistic approach and do not give possibility to free and unlimited movements for people in educational processes. On the other hand, hypertext puts emphasis on writing instead of reading. Emphasizing writing means de-territorializing and moving toward uncertain and multi-dimensional directions in order to create identity and meaning through learners (Rees, 2000). Whereas, in religious education, reading enjoys much importance as readers show more commitment to the text and meaning in such processes.

However, it seems that hypertext creates some challenges for the fundamental principles of traditional religious education processes including "believing along belonging" (Davie, 2002), "undertaking to meaning and hidden messages in religious texts" (Chickering, 1991), "teaching for commitment" (McLaughlin, 1994), "emphasis on 
homogeneity in thought and behavior" (Antone, 2003), "transfer of information and religious knowledge" (Bates, 2005), "model role of teachers" (Gilmore, 1997), and "textbased religious instruction" (Wanak, 2001). Furthermore, hypertexts, by strengthening the process of "delegitimating knowledge" (Lyotard, 1992) and weakening the role of religious meta-narratives, and as a result, negating religious representation, in reality, challenge the legitimization of that part of educational information and knowledge that is based on meta-narratives, including religious meta-narratives. Similarly, the salient emphasis of hyper-textual space in writing, instead of merely reading, leads to the creation of fluid identities for students (Rees, 2000), strengthening, in the process, the idea of "becoming" (Semtesky, 2003), the negation of ordered and dogmatic behaviors (Deleuze, 1987), and, consequently, weakening the predefined religious identities and behaviors that are considered as important challenges to the hyper-textual learning space.

\section{Conclusion}

The proceeding discussion on hyper-textual learning space has aimed to analyze important issues that are basic to learning and meaning making conflicts that arise vis-àvis the authority of constant and predefined texts. These include such things as the "absolute attachment of students to the author's point of views," "compulsive transfer of religious knowledge and information," "emphasis on the role of teacher merely as transferor of knowledge," and finally "emphasis on non-democratic methods of religious learning and education." In addressing these and related issues of the learning process, the simultaneous use of texts and hyper-textual spaces in the religious education process, along with controlling their negative aspects and strengthening positive dimension of the text and hypertext, may be considered the most important obligation for teachers, educational planners, and teaching and curriculum designers. So, the actual challenge facing us should be how we should collectively face and interact with both the positive capabilities and negative outcomes of the textual and hyper-textual spaces.

\section{References}

Antone, H.S (2003). The Challenges of the Globalization to Religious Education: Some Experiences and Reflections from Asia. Asian Feminist Theological Journal, 20(3), 123-129

Barthes, R. (1982). A Barthes Reader. Edited by Susan Sontag New York: Hill and Wang.

Barthes, R. (1977). From Work to Text. In Image, Music, Text. S. Heath (Trans.). New York: Hill and Wang.

Bates. R. (2005). Can We Live Together? Toward a Global Curriculum. Journal of Arts and Humanities in Higher Education. (4). p. 102-104

Berg, S. \& Watt, J.H. (2001). Effects of Educational Setting on Student Response to Structured Hypertext. Journal of Computer-Based Instruction. 6(13). p.124-127.

Birkerts, S. (1994) The Gutenberg Elegies: The Fate of Reading in the Electronic Age. New York: Kegan Paul Publisher.

Bolter, J. (1993). Hypertext and the Classical Commentary. University of Arizona Press: Tucson. 
Burbules, C. and Callister, T. (1996). Knowledge at the Crossroads: Some Alternative Futures of Hypertext Learning Environments. Educational Theory. 47(1), p. 5966.

Bush, V. (1945). As we may think. Atlantic Monthly, July, 1945. p. 101-108.

Chickering, A.W. \& Gamson, Z. (1991). Applying the seven principles of good practice in undergraduate education. New Directions for Teaching and Learning. (47). p. 92-93. San Francisco: Jossey Bass Publishers.

Conklin, J. (1987). Hypertext: An Introduction and Survey. IEEE Computer. 1(9), p. 1740.

Davie, G. (2002). The significance of the religion factor in the construction of a humane and democratic Europe. Symposium Report. Brussels. p.14.

Deleuze, G. (1987). Dialogues. (H. Tomlinson \& G. Burchell, Trans.) New York: Columbia University Press.

Ducrot, O. \& Todorov, T. (1972). Encyclopedic Dictionary of the Sciences of Language. (Catherine Porter, Trans.). Baltimore: Johns Hopkins University Press. p. 356357.

Duncan, B. (1997). Hypertext and Education: Post structural Transformations. Philosophy of Education Yearbook. University of Ilinois.

Edgar, A. \& Sedgwick, P. (1999). Key Concepts in Cultural Theory. New York: Routledge.

Engelbart, D.C. \& English, W.K. (1968.) A Research Center for Augmenting Human Intellect. AFIPS Conference Proceedings. 33(1), p. 56.

Foucault. M. (1977). What is an Author? In D. Bouchard (Ed.) Language, counterMemory, Practice. New York: Cornell University Press. p. 38-41.

Gerald, G. (1992). Beyond the Culture Wars: How Teaching the Conflicts Can Revitalize American Education. New York: Blackwell.

Gilmore, J. (1997). Unitarian universalism. Unitarian Universalist Ministers Association. Boston. p. 83.

Goldman, A.H. (1998) Artistic Interpretation. In E. Craig (Ed) Routledge Encyclopedia of Philosophy. New York: Routledge. p. 503.

Iser, W. (1974). The Implied Reader: Patterns of Communication. In Prose Fiction from Bunyan to Beckett. Baltimore: Johns Hopkins University Press. p. 275.

Jowett, B. (1937). The Dialogues of Plato. New York: Random House. p. 279.

Joyce, M. (1988). Siren Shapes: Exploratory and Constructive Hypertext. Academic Computing. London.

Lacan, J. (1968). The Language of the Self, The Function of Language in Psychoanalysis. (Anthony Wilden, Trans.) Baltimore: Johns Hopkins University Press. p. 39.

Lanham, R. (1993). The Electronic Word: Democracy, Technology, and the Arts. Chicago: University of Chicago Press

Landow, G. \& Delany, P. (1991). Hypertext, Hypermedia and Literacy Studies: The State of Art. Cambridge: MIT Press.

Landow, G. (1997). Hypertext: The Convergence of Contemporary Critical Theory and Technology. Baltimore: John Hopkins University Press.

Lyotard, J.F. (1992.) Postmodern Conditions: A Report on Knowledge. Minneapolis: University of Minnesota Press. 
McKnight, C., Dillion, A, \& Richardson, J. (1996). "User Centered Design of Hypertext and Hypermedia for Education." In Handbook of Research on Educational Communications and Technology. New York: Macmillan.

McLaughlin, T. (1994.) Parental Rights and the Religious Upbringing of Children. Journal of Philosophy of Education. (18): p. 84.

Moulthrop, S. (1994). Rhizome and Resistance: Hypertext and the Dream of a New Culture. In Hyper/Text/Theory. Baltimore: John Hopkins Press.

Nelson, T.H. (1992). Literary Machines. London: Mindful Press.

Nielsen, J. (1990). Hypertext and Hypermedia. Copenhagen: Academic Press.

Pagano, A. (1995). Matters of the Mind. In W. Kohli (Ed.) Critical Conversation in Philosophy of Education. New York: Routledge.

Peters. M. \& Lankshear, C. (1996). Critical and Digital Texts. Educational Theory. 46(1).p. 61.

Popkewitz, T. (1991.) A Political Sociology of Educational Reform. New York: Teacher College Press.

Poster, M. (1995). The Second Media Age. Oxford: Polity Press.

Rees, P. (2000). Time to relax a little: Making time for the interplay of minds in education. Education. 3(13). p. 34.

Renear, Allen. (1997). Out of Praxis: Three (Meta) Theories of Textuality. In K. Sutherland (Ed.) Electronic Text: Investigations in Theory and Method. Oxford: Clarendon Press. p.107-26.

Roy. C. (2003). Teacher in Nomadic Space: Deleuze and Curriculum. New York: Routledge.

Saussure, F. (1966). Course in General Linguistics. Ed. by Charles Bally and Albert Sechehaye, Trans. by Wade Baskin. New York: McGraw-Hill. p. 65.

Seban, J.L. (1998). Roland Barthes. In E. Craig (Ed.) Routledge Encyclopedia of Philosophy. New York: Routledge. p. 657.

Semetsky, I. (2003). Deleuze New Image of Thought, or Dewey Revisited. Educational Philosophy and Theory. 35(1), p.17.

Staninger, S.W. (1994). Hypertext Technology: Educational Consequences. Journal of Educational Technology. July/Aug. p. 142-45.

Wanak, L.C. (2002). Theological curriculum change for the local 21-century context. Journal of Asian Evangelical Theology. (10). p.59.

Whalley, P. (1990). Models of Hypertext Structure and Learning. In Designing Hypermedia for Learning. Edited by D.H. Jonassen and H. Mandl. London: Springer-Verlag.

Wills, D. (1999.) The Nature of Hypertext: Background and Implication for Librarians. Journal of Academic Librarianship. 25(2), p.132. 